\title{
CANHOTOS EM TERRA DE DESTROS: AS DIFICULDADES ESCOLARES ENFRENTADAS PELAS PESSOAS QUE ESCREVEM COM A MÃO ESQUERDA
}

\author{
RANGEL, Ingrid Ribeiro da Gama ${ }^{1}$ \\ SOUZA, Carlos Henrique Medeiros de ${ }^{2}$ \\ NASCIMENTO, Eleonora Campos Teixeira $\mathrm{e}^{1}$
}

\begin{abstract}
RESUMO: Os canhotos são universalmente minoria, por esta razão, enfrentam dificuldades para se adaptarem a um mundo que concebe a humanidade como destra. No âmbito escolar, não são incomuns os relatos de pessoas canhotas que foram - em algum período do processo educativo - estimuladas, ou até mesmo forçadas, a agirem como destras. A presente pesquisa esclarece que esta prática pode resultar na formação de um indivíduo inseguro, introvertido e - consequentemente - com dificuldades cognitivas. As pessoas canhotas também são condicionadas a utilizar materiais pedagógicos projetados para os destros. As carteiras escolares aparecem no topo da lista de reclamações de canhotos que sentem dores e incômodos provocados por um mobiliário inadequado para quem escreve com a mão esquerda.
\end{abstract}

Palavras-chave: Canhoto. Dificuldades escolares. Preconceito.

SUMMARY: Lefties are universally minority, therefore, are struggling to adapt to a world that sees humanity as right hand. In schools, are not uncommon left-handed people the reports that were - at some point in the educational process - encouraged, or even forced, to act as right-handed. This research makes it clear that this practice can result in the formation of an insecure individual, introverted and - consequently - with cognitive difficulties. Left-handed people are also conditioned to use teaching materials designed for right-handers. The school desks appear at the top of the left-handed list of complaints that they feel aches and pains caused by inadequate furniture for those who write with his left hand.

Keywords: Left-handed. Learning difficulties. Preconception.

\section{INTRODUÇÃO}

A sociedade tem apreço pela homogeneização. Para a indústria cultural, por exemplo, é interessante que as pessoas tenham gostos e atitudes iguais. Dessa forma, fica mais facilitada e rentável a fabricação, em massa, de produtos. As instituições de ensino também têm dificuldades em lidar com a diversidade nas salas de aula. Afinal, é mais fácil adotar uma única prática pedagógica para uma turma inteira do que buscar alternativas para necessidades educativas individuais. Neste contexto, quaisquer pessoas que não se enquadrem no estereótipo definido para pessoas "comuns ou normais" estão sujeitas a sofrerem algum tipo de preconceito.

Os canhotos são minorias nas salas de aula e, muitas vezes, são forçados ou estimulados e escreverem com a mão direita. Essa atitude pode acarretar dificuldades no desenvolvimento cognitivo e da linguagem do indivíduo.

O objetivo da presente pesquisa foi investigar as dificuldades enfrentadas pelas pessoas canhotas no âmbito escolar e as consequências dessas dificuldades no desenvolvimento acadêmico e profissional do canhoto.

\footnotetext{
${ }^{1}$ Doutoranda em Cognição e Linguagem - UENF-Universidade Estadual do Norte Fluminense Darcy Ribeiro

${ }^{2}$ Professor doutor e coordenador do Programa de Pós-graduação em Cognição e Linguagem - UENF-Universidade Estadual do Norte Fluminense Darcy Ribeiro
} 
A fim de alcançar o objetivo proposto, foram realizados um levantamento bibliográfico sobre o canhotismo e uma pesquisa exploratória junto aos licenciandos canhotos do Instituto Federal Fluminense, campus Campos-Centro. Por meio de análises qualitativas e quantitativas foi possível identificar alguns problemas escolares enfrentados pelos que têm lateralidade predominante esquerda em um mundo projetado para os destros.

\title{
Por que algumas pessoas são canhotas?
}

Não há ainda um consenso entre os cientistas sobre a causa do canhotismo. Entre as possíveis razões, está a questão do alto nível de testosterona no organismo de algumas gestantes. Sissi Aparecida Martins Pereira (2004, p. 101-102), em pesquisa sobre a lateralidade, afirma que: "Estudos divulgados pela Academia Nacional de Ciência dos Estados Unidos e realizados por Norman Geschwind e Peter Behan revelaram que a testosterona, o hormônio que produz as maiores diferenças entre os sexos, pode ser a causa da sinistralidade". A pesquisadora ainda esclarece que a testosterona pode ser o motivo do número de canhotos entre homens ser, aproximadamente, o dobro do número entre as mulheres.

Outra possível causa para o canhotismo está relacionada à hereditariedade. Em sua tese, Francisca da Silveira (2007) aponta que:

\begin{abstract}
Com base numa grande quantidade de dados familiares ( $\mathrm{N}=2632$ famílias com 8605 prole) coletadas por McKeever (2000), ele relatou certas tendências relacionadas à dominância manual na prole de quatro classes de casais: o pai e a mãe destros, o pai canhoto e a mãe destra, o pai destro e a mãe canhota e ambos canhotos. Entre os achados, foi encontrado um "efeito materno" no sentido de que as mães canhotas (i.e. os casais do tipo destro/canhota) produziram mais filhos canhotos do que filhas canhotas. Em contraste, os pais canhotos (i. e. casais do tipo canhoto/destra) produziram menos filhos canhotos e mais filhas canhotas (2007, p.8).
\end{abstract}

Não é apenas quando se discute a causa do canhotismo que a ciência diverge, outra questão referese à expectativa de vida do canhoto. Springer e Deutsch (1998) assinalam questões controversas do trabalho de Stanley Coren (1993), na Universidade de British Columbia. Segundo os pesquisadores: "Coren estava intrigado com os dados que obtivera, pois mostravam que a proporção de canhotos - 13\% em pessoas com 20 anos de idade - diminuía para menos de 1\%, em pessoas com 80 anos" (SPRINGER; DEUTSCH, 1998, p. 177). Buscando entender os motivos que levariam os canhotos a morrerem mais cedo, Coren (1993) levantou a hipótese de possíveis desordens imunológicas no organismo da pessoa com lateralidade esquerda predominante. Outro fator, segundo o pesquisador, relaciona-se à probabilidade de acidentes entre canhotos:

No estudo feito por meio do parente mais próximo, Halpern e Coren pediram informações com relação à causa da morte e perguntaram se tinha havido lesões relacionadas com acidentes. Eles descobriram que os canhotos tinham seis vezes mais possibilidade de morrer por lesões relacionadas com acidentes do que os destros. Separando os acidentes com veículos, descobriram que os canhotos tinham quatro vezes mais probabilidade de morrer em acidentes ao dirigir um carro. Coren concluiu, por sua análise, que grande parte da diferença entre canhotos e destros com referência à mortalidade pode ser explicada pelos acidentes que diminuem a sobrevivência dos canhotos, em comparação com os destros (SPRINGER; DEUTSCH, 1998, p. 178).

Springer e Deutsch (1998) esclarecem que apesar de o estudo de Halpern e Coren (1989) ser 
importante, é muito controverso. Com a pressão social para que a pessoa seja destra, não se pode precisar, por exemplo, o número de pessoas canhotas, já que várias foram obrigadas a aprender a escrever com a mão direita.

É importante ressaltar que a afirmação de que o canhoto tem quatro vezes mais chances de morrer em um acidente de carro pode levar a sociedade a concluir que pessoas canhotas não podem ser taxistas, por exemplo. No caso dos acidentes de trânsito, deve-se considerar que motoristas canhotos são condicionados a se adaptarem a veículos que são projetados para pessoas destras.

Pesquisas superficiais podem gerar preconceitos em relação a pessoas canhotas. $\mathrm{O}$ economista Joshua Goodman (2014), professor da Universidade de Harvard, fez um estudo com 47 mil pessoas inglesas e americanas e constatou que os canhotos, filhos de mães destras, ganham de 10 a $12 \%$ a menos do que os destros. Segundo o pesquisador: "Canhotos têm mais problemas emocionais e comportamentais, têm mais dificuldades de aprendizagem, como a dislexia, completam menor escolaridade e trabalham em ocupações que exigem menos habilidade cognitiva." (GOODMAN, 2014, p.194). A pesquisa ainda revela que, curiosamente, canhotos filhos de mães canhotas não apresentam maiores índices de problemas cognitivos em relação aos destros. A razão para este dado pode estar nas possíveis causas para o canhotismo. Como já citado, existem estudos que apontam a hereditariedade como causa. Neste caso, a pessoa seria naturalmente canhota. Entretanto, estudos também revelam que problemas na gestação ou no parto poderiam causar o canhotismo. Nesta situação, a pessoa poderia ser canhota porque apresentaria uma lesão em parte do hemisfério cerebral esquerdo, por exemplo.

Evidências sobre específicos fatores que afetam a lateralidade vêm em grande parte a partir de estudos que entendem o canhotismo como uma patologia, que se refere à teoria de que o estresse durante a gestação ou nascimento pode induzir funções hemisféricas, normalmente esquerdas, para deslocar para o hemisfério direito $\left(\mathrm{GOODMAN}^{3}, 2014\right.$, p.196).

\section{Preconceitos enfrentados pelos canhotos}

Se fossem listadas as características de um ser humano "modelo", provavelmente, ele seria descrito como uma pessoa destra. Tal fato ocorreria devido à maioria absoluta de destros em relação a canhotos. Segundo Paula Surek et. al. (2004):

Há uma grande divergência entre os resultados apresentados pelas diferentes investigações que tentaram avaliar a percentagem de esquerdinos em diferentes populações. Os resultados variam entre 1 e $30 \%$ (apontando a maioria para 5 a 10\%). O que se pode concluir desta grande divergência e que e bastante difícil concretizar o que e de fato esquerdismo, dado não ser possível definir qualquer fronteira objetiva entre esquerdismo e destrismo (2004, p.16).

Entre as dificuldades em se precisar a porcentagem de canhotos no mundo, pode-se citar o fato de muitos familiares e educadores forçarem a criança canhota a escrever com a mão direita. Entretanto, pesquisas apontam que a proporcionalidade do número de canhotos em relação a destros quase não sofreu alterações em cinco mil anos:

${ }^{3} \mathrm{O}$ artigo foi originalmente publicado em inglês. A tradução é nossa. 
Na maioria das culturas, $90 \%$ da população utiliza a mão direita para realizar atividades que exijam algum tipo de habilidade. Essas evidências são conhecidas desde os tempos pré-históricos.

Dados descobertos pelos pesquisadores americanos Sally P. Springer e George Deutsch (Cérebro Esquerdo, Cérebro Direito, Summus Editorial: São Paulo, 1993) revelam que um estudo feito com 1.180 trabalhos de arte abrangendo um período de 5.000 anos - que vai do ano 3000 a.C. a 1950 -, mostra que a utilização das mãos direita e esquerda na pintura não sofreu nenhuma mudança ou tendência significativa no decorrer de todo esse tempo (PEYCHAUX, 2003, p.31).

O fato de ser diferente e de não atender ao padrão estimulado para o modelo humano "normal" tem feito com que os canhotos sofram com preconceitos. Para Contreras ${ }^{4}$ (1999, p. 168): "Ser canhoto não é uma desvantagem em si, mas por ser minoria, o canhoto tem que enfrentar um mundo pronto para os destros". Na tentativa de responder à curiosidade de um leitor sobre a perseguição de canhotos, a revista de curiosidades Mundo Estranho publicou, em março de 2015, uma matéria sobre pessoas canhotas. Segundo a revista:

\begin{abstract}
A teoria mais aceita hoje é de que o problema tenha começado há cerca de 350 mil anos entre os povos neandertais europeus, que deram origem às populações ocidentais existentes hoje. Isso porque, no Hemisfério Norte, se você se orientar pela Estrela Polar à noite, o Sol parece se movimentar da direita para a esquerda ao nascer. Logo, a direita ficou como a mão do nascente, que traz a vida, e a esquerda como a que tira, no poente $(2015$, p.48).
\end{abstract}

Embora não se possa precisar o início do preconceito em relação às pessoas canhotas, sabe-se que ele existe. Na Idade Média, canhotos eram considerados contrários a Deus, como se representassem o mal. Maria dos Milagres Diniz (2007) afirma que, neste período, a escola era dominada e orientada pela religião e seus dogmas. A estudiosa relata que "uma criança aprendia a não ser canhota, embora neurologicamente fosse. [...] 'Ser canhoto significava não ser de Deus”' (DINIZ, 2007, p.20).

Considerando a Idade Média como o berço da escola ocidental é possível entender porque até o atual ano de 2015 as pessoas canhotas são vistas com estranhamento. Mesmo com o entendimento de que quem escreve com a mão direita não é amaldiçoada, considera-se o canhoto estranho. Esta estranheza é fruto de uma concepção dogmática, a própria Bíblia ressalta o lado direito como bom: "foi levado ao céu e está sentado à direita de Deus" (Marcos, 16: 19).

Peychaux (2003) esclarece que o preconceito em relação aos canhotos atravessa diferentes gerações e territórios:

É notável que, entre culturas separadas não só pela distância, mas também pelo tempo, parece existir um ponto comum: direito é bom, esquerdo é ruim. Essa constatação revela claramente a existência de uma conspiração contra a mão esquerda, com raras exceções de algumas tribos americanas e da cultura oriental, especialmente a chinesa.

Essa conspiração ou perseguição tem trazido muito sofrimento aos "canhotos" cujos pais, desesperados em corrigir o uso da mão preferencial,

não hesitaram em recorrer aos "castigos corporais" numa tentativa de promover a correção "da mão equivocada".

Na crença popular, a mão esquerda definitivamente tem uma má reputação. Até mesmo quando nos referimos à palavra esquerda, estamos atribuindo a ela uma conotação negativa (PEYCHAUX, 2003, p.33).

${ }^{4}$ Artigo originalmente publicado em espanhol. Tradução nossa.

Nucleus,v.12,n.2,out.2015 


\section{O preconceito disseminado em diferentes línguas}

Os canhotos, na língua portuguesa, também são chamados de sinistros. No dicionário, o signo "sinistro" é sinônimo de sombrio, amaldiçoado, horripilante, entre outros termos negativos (HOUAISS, 2001, p. 2580). Para Lídia Peychaux (2003, p.32), o uso da palavra sinistro traduz-se no entendimento da pessoa canhota como alguém que apresenta falta de habilidade. Ainda segundo a autora: "Em quase todas as línguas, os termos "esquerdo" ou "canhoto" possuem significados depreciativos, que acabam por gerar uma série de outros nomes que carregam em si essa conotação negativa como, por exemplo, desajeitado, inapto, pernicioso, etc.” (PEYCHAUX, 2003, p.32).

Como ressalta a autora, em vários idiomas a denominação dada à pessoa canhota não é positiva. Em latim, o canhoto era chamado de "sinistre", o que explica o uso da palavra em português, idioma neolatino. Em espanhol, usa-se zurdo que também pode significar um ser torpe. Ainda em espanhol, a palavra esquerda conota "o profano, o mal, o sinistro" (CONTRERAS, 1999, p. 168).

Em inglês, como em português, uma pessoa correta é right (direita). Esse idioma apresenta como sinônimo de canhoto a palavra clumsy, que significa desajeitado (CONTRERAS, 1999, p. 168). Ainda em inglês, pode-se chamar o canhoto de stud, que como verbo no modo passado perfeito significa: "dar uma topada" (PARKER; STAHEL, 1998, p.537).

Em francês, canhoto é gauche, que também pode significar: "desajeitado; constrangido; mal feito" (CORRÊA, 1965, p. 269). O termo tem como sinônimo a palavra maladroit que significa: "desajeitado(a)" (LAROUSSE, 2008, p.209).

Em italiano, canhoto também pode ser sinônimo de sinistro. O idioma também permite a utilização das palavras manco "falta, prejuízo" e mancino "larápio" (AMENDOLA, 1976, p. 474). Larápio, em português, significa "pessoa desonesta".

A denominação de canhotos, em diferentes idiomas, com conotação negativa ratifica a afirmação de que as pessoas que escrevem com a mão esquerda sofrem preconceitos em várias culturas.

\section{A resistência à mão esquerda no âmbito escolar}

Forçar um canhoto a escrever com a mão direita pode causar sérios danos ao desenvolvimento do indivíduo. O filme $O$ discurso do Rei, vencedor do Oscar de melhor filme de 2011, retrata o problema de gagueira enfrentado pelo rei George VI. Em fevereiro de 2011, a Revista Época reuniu pessoas gagas e especialistas para discutir a questão da gagueira à luz do filme britânico. Durante o debate, a fonoaudióloga especializada em gagueira, Sandra Merlo, explicou que: "A questão da emoção, ela é importante sim. Não como causa, mas depois que a gagueira já está instalada, a emoção pode vir a piorar a fala". No filme, não é explicitamente apresentada a causa da gagueira do rei. Entretanto, há um diálogo entre Lionel Logue (interpretado por Geoffrey Rush), profissional que ajuda a solucionar as dificuldades de fala do rei, e George (interpretado por Colin Firth) que fornece indícios sobre a relação de o rei ter sido forçado a ser destro com a gagueira.

\footnotetext{
- Você é naturalmente destro?

_ Canhoto. Fui punido e agora eu uso a mão direita.

_ Sim, isso é muito comum nos gagos.
}

O diálogo, que ocorre no último quarto do filme, leva a dedução de que a gagueira de George seja consequência de "correções" feitas na infância. George seria o que Osvaldo Contreras (1999, p.168) 
chama de canhoto contrariado: "canhotos contrariados são os corrigidos por castigos ou técnicas de reeducação psicomotora que desenvolvem o uso da mão direita".

Ao longo da peça cinematográfica, é apresentado um postulante a rei que não apenas tem dificuldades com a fala, mas apresenta também problemas emocionais. O membro da família real que procura Lionel é inseguro, teme o reinado e não apenas falar em público. $\mathrm{O}$ fato de ter sido obrigado a escrever com a mão direita pode ter contribuído para que George se transformasse em um homem inseguro. Gessen (2003) explica que as pessoas canhotas que são forçadas a agirem como destras podem desenvolver problemas emocionais.

Apesar das práticas contra os canhotos estarem reduzindo, há resultados negativos sobre esta condição que parecem ser inalterados ao longo do tempo. Não é de estranhar que uma criança canhota que tenha sofrido ataques por sua condição, chegue a mudar de atitude passe a se sentir frustrada, incompreendida, insegura e introvertida. Ser canhoto não tem nada a ver com deficiência física ou psicológica (GESSEN, 2003, p.298).

Ao longo do filme, quando George ganha autonomia e autossegurança, ele melhora a sua capacidade de comunicação oral. Sobre a insegurança de George VI, a fonoaudióloga Sandra Merlo (2011), no documentário produzido pela Revista Época, comenta que: "Quando a pessoa tem algum tipo de emoção, que ela tem uma ambiguidade: não faço ou faço (...) a gagueira tende a piorar. Por quê? Porque, digamos assim, áreas do cérebro que estão relacionadas com a emoção inibem as áreas de fala".

A obra Memórias de alfabetização, organizada por Eliane Peres (2007), traz experiências de várias pessoas no período de alfabetização. Entre as pessoas entrevistadas, está a professora Ana Berenice dos Reis que relata a Magda Benati os traumas sofridos na ambiente escolar por ser canhota:

$\mathrm{Na} 3^{\mathrm{a}}$ série eu tive uma outra professora o oposto desta. Porque ela era magrinha alta, usava óculos, também era morena e fez... um estrago muito grande na minha vida. Foi a partir daí que a minha letra bagunçou e não corrigi até hoje. Pode ver que a minha letra é horrorosa. Ela, ela... Enquanto a primeira nos aceitava como nós éramos e apenas corrigia os erros que nós cometíamos, esta segunda professora, por exemplo, ela implicava muito comigo porque eu era canhota. Então porque eu era canhota eu era filha do diabo, eu jamais ia poder ser professora porque eu era mau exemplo. Eu ficava sempre no recreio de castigo tendo que fazer... encher folhas e folhas com a mão direita. Ia sempre com temas pra casa para que... com a observação pra minha mãe cuidar pra que eu não usasse a mão esquerda. E aí como eu era canhota, e eu não deixei de ser canhota, realmente acabou que eu não fiquei com a letra boa nem com a esquerda nem com a direita, muito pelo contrário, bagunçou tudo. E bagunçou inclusive... criou muitos problemas assim, afetivos e emocionais, eu tinha um medo dela, terrível... A discriminação contra o canhoto era uma coisa muito séria por parte dessa professora. (PERES, 2007, p.139).

Ana Berenice ainda relata que não foi imediatamente para o magistério por causa da professora que a discriminou. Depois de ter estudado Física, resolveu aceitar um convite de outro professor para lecionar. A entrevistada afirma que, na ocasião, lembrou-se da professora da $3^{\text {a }}$ série: "Ah! eu não posso ir pro magistério, pois eu vou...” (PERES, 2007, p.140). Pode-se notar que a entrevistada encontrou dificuldades em vencer os problemas oriundos da discriminação da professora.

Na mesma obra, a entrevistada Luzia Faraco Ramos declara a Antônio Alves ter enfrentado problemas por ser canhota: "fui obrigada a escrever com a mão direita, não me lembro de nada muito grave, somente que não havia nenhuma possibilidade de pegar o lápis na mão esquerda! Hoje, eu só uso a mão direita para escrever, e não tenho a lateralidade incorporada, direita e esquerda são somente 
palavras..." (PERES, 2007, p.20). O fato de Luzia, mesmo sendo canhota, ter sido obrigada a escrever como destra pode ter feito com que ela não pudesse desenvolver seu sistema psicomotor de forma satisfatória.

\section{Pesquisa com licenciandos canhotos do IF-Fluminense}

Entre os dias 16 e 20 de março de 2015, foi realizada uma pesquisa exploratória junto aos alunos dos Cursos de Licenciatura do Instituto Federal Fluminense, Campus Campos-Centro. Alunos de 20 das 24 turmas responderam a um questionário com 8 questões, 6 de múltipla escolha e 2 abertas. Ao todo, 12 canhotos participaram da pesquisa. Dentre eles, 9 tinham até 25 anos, 2 entre 26 e 35 anos e 1 declarou ter mais de 45 anos.

Quando questionados se já tinham sofrido algum tipo de preconceito por ser canhoto, 4 dos 12 questionados responderam que sim. Considerando a predominância da faixa etária dos questionados (a maioria tem menos de 26 anos), 33\% terem respondido que já sofreram preconceito é um número alto. Afinal, a literatura sobre o preconceito em relação aos canhotos aponta que a prática era mais comum até o início do século XX. Entretanto, a maior parte dos questionados que disse ter sofrido preconceito oriundo do canhotismo nasceu depois de 1990. Cinco dos 12 questionados declaram terem sido incentivados, na escola, a escrever com a mão direita, mesmo sendo canhotos.

Quando questionados se, na escola, tinham acesso a carteiras próprias para canhotos, todos declaram que não contavam com um mobiliário adequado no ambiente escolar. A falta de carteiras escolares adequadas pode causar danos posturais. Nove dos 12 questionados declararam ter sentido dores no corpo em consequência do uso de carteiras próprias para destros.

Nas duas questões discursivas abertas, as pessoas também salientaram o problema das carteiras escolares. Quando questionados se enfrentam alguma dificuldade específica por ser canhoto, metade dos licenciandos evidenciou o problema da carteira: "Só no uso das carteiras durante toda minha vida de estudante. Às vezes entro na sala e não encontro carteira que seja favorável para quem é canhota" (L3 ${ }^{5}$ ). Também na questão que pedia uma proposta de mudança para deixar a vida da pessoa canhota menos complicada, a disponibilização de carteiras apropriadas para canhotos foi ressaltada por 8 dos 12 licenciandos: "Mudaria as carteiras das salas que, de certa forma, causam desconforto nos alunos canhotos" (L4).

A questão das carteiras, evidenciada pela maioria dos questionados, é tema do Projeto de Lei $\mathrm{N}^{\mathrm{o}}$ 2914/2010, da Assembleia Legislativa do Estado do Rio de Janeiro (ALERJ):

Art. $1^{\text {o }}$ - Fica obrigatória à disponibilização em salas de aula de cadeiras de braço para alunos canhotos matriculados em instituições de ensino na rede pública ou privada do Estado do Rio de Janeiro:

Parágrafo Único - As atribuições do caput se aplicam às instituições que realizem ocasionalmente palestras, concursos ou quaisquer atividades acadêmicas.

Art. $2^{\circ}$ - O número de cadeiras destinadas aos alunos canhotos, corresponderá a $10 \%$ (dez por cento) dos alunos matriculados, mantendo-se em estoque, em perfeito estado de conservação para uso imediato, as não utilizadas. (RIO DE JANEIRO, 2010).

No âmbito federal, o Projeto de lei no. 7.109/14: "altera a Lei no 9.394, de 20 de dezembro de 1996 (Lei de Diretrizes e Bases da Educação Nacional), para dispor sobre a garantia de mobiliário adequado a

\footnotetext{
${ }^{5}$ A fim de resguardar a identidade dos questionados, optou-se por identificá-los com L (Licenciando) seguido de um numeral $(1,2,3 \ldots)$.
} 
alunos destros e canhotos e a alunos com deficiência, em todas as instituições de ensino.” (BRASIL, 2014, p. 14).

O projeto de lei do governo federal contempla os canhotos apenas no âmbito escolar. Já o proposto pela ALERJ, dispõe também sobre concursos e demais ocasiões acadêmicas. A aprovação dos projetos, como apontado na pesquisa com os licenciandos do IF-Fluminense, é importante para o desenvolvimento escolar da pessoa que escreve com a mão esquerda. O pesquisador José D'Assunção Barros (2005, p. 365) acredita que:

Se não existisse um certo número de carteiras escolares para os alunos canhotos, eles teriam de enfrentar dificuldades adicionais ou grandes incômodos para escrever. Neste caso, estariam sofrendo uma desigualdade relativa ao acesso às possibilidades de executar atividades relacionadas à escrita. (BARROS, 2005, p.365).

Outro objeto que incomoda os canhotos é o caderno escolar. O espiral, posto à esquerda, dificulta o desenvolvimento da escrita e atrapalha a caligrafia. Metade dos questionados relatou que o espiral do caderno incomoda. Ao ser questionado se enfrenta alguma dificuldade específica por ser canhoto, L10 afirmou: "Sim, quando utilizo o caderno, as molas incomodam bastante".

As maiores dificuldades enfrentadas pelos canhotos são referentes aos objetos fabricados para os destros. Contreras (1999, p.168) ressalta algumas das dificuldades enfrentadas pelos canhotos: "O uso de talheres, a escrita ocidental da esquerda para a direita, as torneiras das pias, os puxadores das portas, a rotação das portas giratórias, os lemes de veículos, os caça-níqueis, a corda dos relógios, a marcha dos carros, as carteiras escolares, etc.".

Na ficção, o personagem Ned Flanders, dos "Simpsons" criou a sua loja "Leftortum" - ou como livremente traduzido para a língua portuguesa - "Canhotório". Na animação, o personagem, que sofria por ser canhoto, teve a ideia de abrir a loja com produtos exclusivos para esquerdinos. Não são muitas lojas no "mundo real" que vendem objetos "adaptados". Além da dificuldade de encontrar as lojas, os canhotos têm de gastar mais do que os destros para adquirir objetos como tesouras e abridores de lata.

A fim de tentar compreender se o fato de ser canhoto afetou a fala dos questionados, foi perguntado se eles apresentavam alguma dificuldade em se comunicar oralmente. Apenas uma pessoa declarou ter problemas: "Acredito que interfira além do empecilho da escrita. Afeta um pouco o psicológico também" (L1).

\section{CONSIDERAÇÕES FINAIS}

Os canhotos, ao longo da vida escolar, enfrentam muitas dificuldades. Dentre elas, vale ressaltar o preconceito por parte de alguns responsáveis e professores que - por julgarem o canhotismo um problema- tentam forçar a pessoa canhota a escrever com a mão direita. Outro problema revelado na pesquisa é a falta de materiais pedagógicos e mobiliários adequados para canhotos.

A literatura que trata do canhotismo não é unânime ao afirmar que o canhoto apresenta problemas cognitivos. Após a pesquisa bibliográfica, pode-se considerar o fato de ser canhoto em si não é, normalmente, um problema. O que ocorre é que o canhoto tem de enfrentar dificuldades escolares que o destro não enfrenta. $\mathrm{O}$ tempo destinado a se habituar, mesmo sentindo dores posturais, a escrever sentado em carteiras destinadas a destros e a necessidade de se adaptar a escrever com a mão direita, mesmo sendo canhoto, podem ampliar o período destinado - por exemplo - à alfabetização. 
A pesquisa exploratória não evidencia deficiências cognitivas causadas pelo canhotismo, mas sim a dificuldade das escolas em promover ambientes e práticas pedagógicas que privilegiem todas as pessoas, canhotas ou não.

\section{REFERÊNCIAS}

AMENDOLA, J. Dicionário Italiano-Português. 2.ed. São Paulo: Hemus, 1976.

ARAÚJO, A. V. de. A concepção de corpo dos professores que ensinam Educação Física aos estudantes com deficiência intelectual. Londrina: Universidade Estadual de Londrina, 2013. Disponível em:

<http://www.uel.br/cef/demh/graduacao/arquivosdownload/TCCs_em_PDF_2013/concep.pdf $>$ A cesso em: 23 mar. 2015.

BARROS, J. A. Igualdade, desigualdade e diferença: em torno de três noções. Análise Social, v. XL, n.175, 2005. Disponível em:

$<$ http://analisesocial.ics.ul.pt/documentos/1218709941G9oFF7ya2Ux18EW0.pdf >. Acesso em: 10 mar. 2015.

BÍBLIA. Bíblia Sagrada. Trad. Centro Bíblico Católico - Mediante a versão dos Monges de Maredsous (Bélgica). 16 ed. São Paulo: Ave-Maria, 1998.

BRASIL (País). Diário da Câmara dos Deputados. Ano LXIX, n 193, 13 dez. 2014. Disponível em: <http://imagem.camara.gov.br/Imagem/d/pdf/DCD0020141213001930000.PDF >. Acesso: 24 mar 2015.

CHAUÍ, M. Brasil: mito fundador e sociedade autoritária. São Paulo: Fundação Perseu Abramo, 2000.

CONTRERAS, O. C. El mundo del zurdo. Rev Colomb Psiquiatr v. XXVIII, n. 2, 1999.

Disponível em: <http://www.scielo.org.co/pdf/rcp/v28n2/v28n2a09.pdf>. Acesso em: 25 mar 2015.

COREN, Stanley. The Left-hander Syndrome: the causes e consequences of left - handedness. New York: Vintage Books, 1993.

COREN, Stanley.; HALPERN, D.. The perils of living in a right-handed world. New Science. 28 Oct 1989.

CORRÊA, R. A. Dicionário escolar Francês-Português, Português-Francês. 3ed. Mec, 1965.

DINIZ, M. M. F. Um olhar direcionado às dificuldades de aprendizagem. João Pessoa:

Universidade Federal da Paraíba - UFPB, 2007. Disponível em:

<http://bdtd.biblioteca.ufpb.br/tde_arquivos/12/TDE-2010-03-29T130648Z-

385/Publico/arquivototal.pdf $>$. Acesso em: 10 mar. 2015.

GESSEN, V; GESSEN, M. M. El niño zurdo. Trasvase, ano 7, n. 22, 2003. Disponível em: <http://www.saber.ula.ve/bitstream/123456789/19799/1/articulo26.pdf >. Acesso em: 25 mar 2015. 
GOODMAN, J. The Wages of Sinistrality: Handedness, Brain Structure, and Human Capital Accumulation. Journal of Economic Perspectives. V. 28, n. 4 - Fall 2014-Pages 193-212. Disponível em: 〈http://pubs.aeaweb.org/doi/pdfplus/10.1257/jep.28.4.193 >. Acesso em: $21 \mathrm{mar}$. 2015.

HOUAISS, A.; VILLAR, M. S.; FRANCO, F. M. M. Dicionário Houaiss da Língua Portuguesa. Rio de Janeiro: Objetiva, 2001.

LAMAS, J. É verdade que os canhotos já foram perseguidos?. Mundo estranho. mar. 2015.

LAUROSSE. Laurosse Dicionário Francês-Português, Português-Francês. 2ed. São Paulo, SP: Laurosse, 2008.

LOPES, L. O rei também pode ser gago. Revista Época online. 03 mar. 2011. Sociedade. Disponível em: 〈http://revistaepoca.globo.com/Revista/Epoca/0,EMI214535-15228,00.html〉. Acesso em: 20 mar. 2015.

PARKER, J; STAHEL, M. Password: English Dictionary for speakers of Portuguese. 2.ed. São Paulo: Martins Fontes, 1998.

PEYCHAUX, L. Acessando o hemisfério direito do cérebro: a arte como ferramenta para desenvolver a criatividade. Rio de Janeiro: Papel Virtual, 2003.

PEREIRA, S. A.M. A relação entre lateralidade e flexibilidade. Revista Mineira de Educação Física. v. 12, n. 1, 2004, p. 101-112. Disponível em:

<http://www.revistamineiradeefi.ufv.br/artigos/arquivos/d6b2eccad98a34da8ba566c91656a5b0.p df> Acesso em: 21 mar. 2015.

PERES, E. (Org.). Memórias de alfabetização. Pelotas: Seiva, 2007.

RIO DE JANEIRO (Estado) Projeto De Lei No 2914/2010. Disponível em: <http://alerjln1.alerj.rj.gov.br/scpro0711.nsf/1061f759d97a6b24832566ec0018d832/1dda850b15 536188832576c1005cf098? OpenDocument >. Acesso em: 24 mar de 2015.

SEIDLER, David (Roteiro). O Discurso do Rei. São Paulo: Paris Filmes, 2011.

SILVEIRA, F. M. da. Desempenho na grafia e na direção grafológica em função da postura manual e dominância manual em destros e canhotos em famílias de renda baixa e média. Belém: Universidade Federal do Pará, 2007.

SPRINGER, S. P; DEUTSCH, G. Cérebro esquerdo, cérebro direito. Tradução: Thomaz Yosshiura. São Paulo: Summus, 1998.

SUREK, A. P.et al. Projeto de viabilidade econômica Mundo Canhoto. Curitiba: Universidade Tuiuti do Paraná, 2004. Disponível em: <http://tcconline.utp.br/wpcontent/uploads//2013/09/PROJETO-DE-VIABILIDADE-ECONOMICA-MUNDO.pdf $>$. Acesso em 12 mar. 2015. 